\title{
Neurophysiological Monitoring during Surgery on the Central Nervous System: The Role of Evoked Responses
}

Soghomonyan $\mathrm{S}^{1 *}$, Sandhu GS ${ }^{1}$, Stoicea $\mathrm{N}^{1}$, Kurnutala $\mathrm{LN}^{2}$, Cotterman-Hart $\mathrm{S}^{3,4}$, Christofi FL ${ }^{1}$, Bergese $\mathrm{SD}^{1,3}$

${ }^{1}$ Department of Anesthesiology, Wexner Medical Center, Ohio State University, Columbus, OH, USA.

${ }^{2}$ Department of Anesthesiology, University of Mississippi Medical Center, Jackson, Mississippi, USA.

${ }^{3}$ Department of Neurological Surgery, Wexner Medical Center, Ohio State University, Columbus, OH, USA.

${ }^{4}$ Department of Neurology, Wexner Medical Center, Ohio State University, Columbus, OH, USA.

\begin{abstract}
Neurosurgical, orthopedic and vascular interventions may be associated with an inherent risk of ischemia and structural damage to the central nervous system. Along with other modalities used to monitor the intraoperative nervous function, registration of evoked responses is intended to provide real-time feedback about the functional integrity of the central nervous system and help to prevent avoidable trauma during surgery. In this review, the principal indications and limitations of monitoring various evoked responses during surgery on the brain and spinal cord are discussed. Current approaches, recent advances and problems associated with intraoperative rhomboid fossa mapping, cranial nerve stimulation and electrooculographic monitoring are presented as well. The authors discuss the effects of general anesthesia on evoked responses and possible ways to avoid signal variability during registration. It is emphasized that only with close cooperation between neurosurgeons, anesthesiologists and neurophysiologists it will be possible to maximize the benefits of intraoperative monitoring of evoked responses and avoid misinterpretation of the results.

Keywords: Neurophysiological Monitoring; Evoked Potentials; Electrooculography; Rhomboid Fossa Mapping; Cranial Nerve Stimulation.

Abbreviations: AEP: Auditory evoked potential(s); AVM: Arterio-venous malformation; BAEP: Brainstem acoustic evoked potential(s); CBF: Cerebral blood flow; CMAP: Compound muscle action potential(s); CN: Cranial nerve(s); CNAP: Compound nerve action potential(s); CNS: Central Nervous System; CPA: Cerebellopontine angle; EEG: Electroencephalography; EMG: Electromyography; EOG: Electrooculography; EP: Evoked Potentials; HFS: Hemifacial spasm; ICP: Intracranial pressure; INM: Intraoperative neuromonitoring; IPL: Interpeak latency; MAC: Minimal alveolar concentration; MEP: Motor evoked potential(s); MLAEP: Mid-latency auditory evoked potential(s); MR: magnetic resonance; MVD: Microvascular decompression; SEP: Sensory evoked potential(s); SHA: Superior hypophyseal artery; SSEP: Somatosensory evoked potential(s); TcMEP: Transcranial motor evoked potential(s); VEP: Visual evoked potential(s); TES: Transcranial electrical stimulation; TMS : Transcranial magnetic stimulation.
\end{abstract}

\section{*Corresponding Author:}

Suren Soghomonyan MD, Ph. D.,

Department of Anesthesiology, Wexner Medical Center, The Ohio State University, Doan Hall N411, $410 \mathrm{~W} 10^{\text {th }}$ Avenue, Columbus, OH 43210 , Tel: (614) 366-4805

Fax: (614)-366-1943

E-mail: suren.soghomonyan@osumc.edu

Received: June 11, 2015

Accepted: July 06, 2015

Published: July 13, 2015

Citation: Soghomonyan S et al., (2015) Neurophysiological Monitoring during Surgery on the Central Nervous System: The Role of Evoked Responses. Int J Anesth Res. 3(6), 119-129. doi: http://dx.doi. org $/ 10.19070 / 2332-2780-1500031$

Copyright: Soghomonyan $\mathbf{S}^{\odot}$ 2015. This is an open-access article distributed under the terms of the Creative Commons Attribution License, which permits unrestricted use, distribution and reproduction in any medium, provided the original author and source are credited.

\section{Introduction}

Real-time intraoperative assessment of central nervous structures, intends to decrease the perioperative morbidity and improve the outcome.

Several approaches have been used to monitor the intraoperative neurological function including patient awakening, and awake craniotomy under local anesthesia [1-5]. However, general anesthesia is required in majority of cases necessitating application of neuromonitoring. The intraoperative electroencephalography (EEG) is discussed elsewhere [6-9]. The current review focuses on intraoperative monitoring of evoked responses during interventions on the central nervous system (CNS).

\section{The Basics}

Depending on proximity of the recording electrode to the signal generator, evoked potentials (EP) are categorized into near and 
far field potentials $[10,11]$.

EP are characterized by amplitude, polarity, absolute and interpeak latencies (IPL), and central conduction time (applicable to somatosensory EP (SSEP) [12-14].

Sensory EP (SEP) are generated by stimulation of sensory receptors, nerves or tracts, while motor evoked responses - by transcranial electrical, magnetic or direct stimulation of the motor cortex, corticospinal tracts, brainstem, cranial nerves $(\mathrm{CN})$, nerve roots or spinal cord.

EP may occasionally be associated with false-positive or falsenegative results [9, 15-17]. Clinical judgment and understanding the limitations of neuromonitoring modalities are required for correct interpretation of intraoperative EP changes. The optimal warning signal threshold level should be defined as choosing increasingly stringent warning criteria trades specificity for sensitivity.

The EP peak amplitudes are significantly smaller compared to EEG and require multiple stimulations, frequency filtering and signal averaging to be extracted from the underlying noise [12, 13]. Commonly, relative rather than absolute signal amplitude changes are used to assess intraoperative EP dynamics [13, 19, 20]. A latency increase $(>10 \%)$ or a decrease in peak amplitude below a conventional threshold level (usually $<50 \%$ ) are considered as significant and alert for potential risk of ischemia or structural damage $[13,19,21]$. However, these criteria are not based on empirical evidence, and are disputed by others.

Factors affecting intraoperative EP include ambient electrical noise, electrode type, impedance, placement site, their movement and dislodgement, equipment malfunction, preexisting neurological pathology, anesthesia, drugs, hypothermia, arterial hypotension, development of pneumocephalus, etc., [10, 15, 16, 21].

SSEP are used to monitor the integrity of ascending somatosensory pathways. The intensity, frequency and duration of stimulation depend on the nerve stimulated [12]. The evoked response is then measured along the somatosensory ascending pathway at Erb's point (brachial plexus), C2-C7 vertebrae, or from the scalp over the primary somatosensory cortex [13]. A variation of this technique is the spinal cord-to-scalp stimulation [23].

SSEP are insensitive to motor impairment [15]. However, isolated intraoperative motor pathway ischemia and trauma rarely happen, and SSEP are being effectively used to monitor spinal function during surgery. Importantly, the lower extremity SSEP propagation includes additional components passing via spinocerebellar pathways, which may explain the method's sensitivity to ischemia beyond the somatosensory zone (as cited in [11]).

Median nerve SSEP is not diagnostic for interventions below C8 [13], and tibial or peroneal nerve SSEP are used in such cases. Unlike upper extremity SSEP, stimulation of the posterior tibial nerve evokes a bilateral EP, probably due to the position of the somatosensory cortex in the longitudinal fissure [24].

Figure 1. Normal transcranial motor evoked potentials (TcMEP). Anesthesia: desflurane combined with remifentanil, propofol and dexmedetomidine. The negative waves deflect up, and the positive signals deflect down.

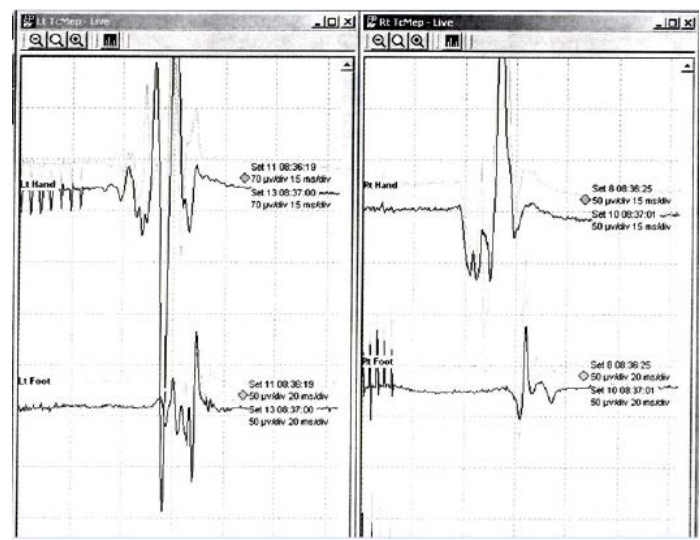

Figure 2. Absent lower extremity transcranial motor evoked potentials (TcMEP) in a patient diagnosed with spinal epidural abscess. Anesthesia: sevoflurane, remifentanil infusion. The negative waves deflect up, and the positive signals deflect down.

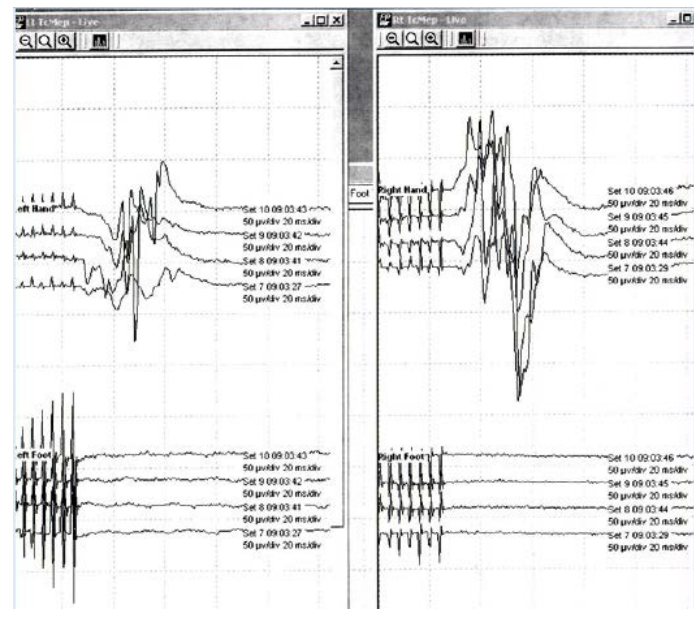


Motor evoked potentials (MEP) are used to monitor the descending motor pathways (Figure 1 and 2). Two commonly used methods of MEP registration are transcranial electrical motor evoked potentials (TcMEP) and transcranial magnetic stimulation (TMS). The latter method is mostly used for preoperative topographic assessment. Direct cortical stimulation may be applied during surgery within highly eloquent cortical regions [3] or during surgery on the brainstem and $\mathrm{CN}$.

MEP is recorded at the spinal level (D- and I- waves) or from periphery - compound muscle action potential (CMAP) [13]. Smaller muscles of the hand or foot are recommended as sites for electromyography (EMG) and CMAP recording due to richer innervation. However, modern day multichannel recordings have the potential of detecting root-level injuries rather than just gross insults to the spinal cord. The MEP amplitude changes are more sensitive and specific than latencies [25].

Acoustic evoke potentials (AEP) are produced by applying click sound stimulation to the ears with subsequent recording of EP from vertex/mastoidal electrodes. A background "white" noise is applied to the contralateral ear to mask conductive noise stimulation. More commonly in the operating room, earphones with foam inserts are used to block external noise as well as minimize the crosstalk to the contralateral ear. Traditional AEP require a relatively long averaging period of approximately 90 seconds for each ear $[9,26]$. Stable acoustic brainstem responses strongly correlate with preserved postoperative hearing, while their loss may not reliably predict the hearing outcome.

Brainstem auditory evoked potentials (BAEP) are commonly used to monitor the auditory pathways and brainstem integrity during surgery [10]. Most commonly, a 50\% decrease in BAEP peak amplitudes and $0.5-1.0 \mathrm{msec}$ increase in latencies on 2-3 consecutive trials are used as warning criteria during monitoring.

Electrocochleography (ECoG) and CN VIII compound nerve action potentials (CNAP) are used to monitor the acoustic nerve function during surgery. Their signals are significantly stronger compared to BAEP, and less averaging is required $[13,26]$.

Mid-latency auditory evoked potentials (MLAEP) are not applicable for intraoperative monitoring of auditory nerves because of high sensitivity to anesthetics. However, they may be used to measure the depth of anesthesia $[11,27,28]$.

Visual evoked potentials (VEP) are monitored during procedures when visual pathways are at risk. However, this modality is not commonly used because of notorious variability under anesthesia. Intraoperatively, VEP are recorded from the vertex and occipital electrodes after a flash light stimulation to retina. The P100 component of VEP is associated with visual cortical activity. However, no exact neural generators can be linked to P100 because of polysynaptic nature of signal propagation.

\section{Effects of anesthesia on EP}

Sensitivity of EP to anesthesia depends on the modality and pharmacological characteristics of anesthetic drugs. VEP are especially sensitive to general anesthesia due to the polysynaptic nature of signal transmission. SSEP are less sensitive, while the BEAP are relatively resistant to commonly used anesthetic doses.
A more detailed discussion of the interaction between general anesthesia and EP is out of the scope of this article and can be found elsewhere $[10,29,30,31]$.

EP suppression induced by inhalational anesthetics is more pronounced compared to intravenous drugs $[10,13]$. Nevertheless, low doses of inhalational agents (0.5 MAC for TcMEP and up to $0.8 \mathrm{MAC}$ for SSEP) can be effectively used during surgery combined with low-dose infusions of remifentanil $(0.05 \mathrm{mcg} /$ $\mathrm{kg} / \mathrm{min}$ ), propofol (50 $\mathrm{mcg} / \mathrm{kg} / \mathrm{min}$ ), and/or dexmedetomidine $(0.2-0.3 \mathrm{mcg} / \mathrm{kg} / \mathrm{h})[30,33]$. Their use will stabilize the anesthesia and reduce the risk of patient movements during critical stages of surgery.

Kempton and colleagues (2010) applied balanced anesthesia with isoflurane, $\mathrm{N}_{2} \mathrm{O}$ (in 94\%), propofol (in 4.5\%) and vecuronium for partial muscle relaxation in 247 patients undergoing scoliosis correction [34]. In 91\%, the investigators recorded monitorable responses with anesthetic MAC levels $>0.5$, while TcMEP could be recorded in $39 \%$ with MAC $>1.0$.

Sevoflurane, owing to its solubility profile and fast elimination, is the induction agent of choice in young children, when EP monitoring is planned [35].

Most intravenous hypnotics suppress the EP in a dose-dependent way, while etomidate and ketamine increase SSEP amplitudes [10]. Opioid-induced EP suppression is proportional to lipophilicity and dose of the drug. In commonly used doses, opioids have minimal effects on EP and can be safely used during monitoring. High doses of remifentanil cause a 20\%-80\% decrease in P37 peak amplitude of SSEP with $<10 \%$ latency increase [36].

Benzodiazepines produce mild to moderate EP inhibition [10], which is less pronounced compared to inhalational agents. Administration of remifentanil and midazolam reduces the anesthetic requirements and increases the efficacy of EP registration [37]. Dexmedetomidine has been proposed as a useful adjunct to total intravenous anesthesia (TIVA) during monitoring [38]. It reduces the propofol requirements without affecting the anesthesia quality. The drug can be effectively combined with ketamine and fentanyl during intraoperative neuromonitoring (INM) [39].

Lidocaine $(1.5 \mathrm{mg} / \mathrm{kg} / \mathrm{h})$ is an effective adjunct to general anesthesia during EP monitoring as it reduces anesthetic requirements and the incidence of patient movements in response to surgical stimulation [40].

MEP are more sensitive to inhalational anesthetics and relaxants, and therefore, anesthetic conditions optimized for TcMEP will usually produce acceptable SSEP [29, 41, 42]. Partial muscle relaxation can be used during MEP monitoring, which may even improve the signal quality, however, most of neurophysiologists refrain from using relaxants after tracheal intubation [13, 43, 44]. Direct cortical stimulation as well as increasing stimulation intensity and frequency can help to overcome some of the volatile anesthetic-induced MEP depression [29].

Another factor influencing the quality of EP monitoring is anesthesia stability. Bolus drug injections and changes in inhalational anesthetic dose may result in long-lasting EP suppression and should be avoided [29, 38, 41, 44, 45]. Besides choosing the right 
drug combination, it is important to keep the anesthesia depth and drug administration rate stable. When properly conducted, both inhalation and intravenous anesthesia generally yield anesthetic conditions appropriate for INM [41].

Intraoperative EP signal tends to degrade over time independent of anesthetic dose [46]. Signal fade is proportional to the anesthesia length and is more pronounced in young children and myelopathic patients [37, 46]. Differentiation between anesthesiarelated signal fading and event-related EP degradation may be problematic.

Physiologic parameters should be maintained stable throughout surgery to exclude any interference with INM.

\section{Monitoring during spinal surgery}

Spinal surgery carries the inherent risk of tissue damage with development of postoperative neurological deficit. INM during spinal interventions intends to reduce such risk by providing a real-time feedback to the surgeon [47]. Based on INM, modifications in anesthesia and surgery are made to avoid irreversible tissue damage [48].

Since their introduction, SSEP have become the most commonly used monitoring method in spinal surgery $[12,47]$. Their main advantage over MEP is continuous registration throughout the anesthesia and surgery (Figure 3). SSEP do not preclude intraoperative use of muscle relaxants, which makes anesthesia management easier. Limitations of the method include sensitivity to anesthesia, hemodynamic changes and hypothermia [10, 49, 50].

The optimal stimulation intensity to induce SSEP is one that evokes a visible muscle twitch or a muscle twitch plus sensory threshold. It is determined by evoking a maximal amplitude nerve action potential recorded at Erb's point - Fpz (median nerve) or popliteal fossa - medial condyle of tibia (tibial nerve) [51].

In young children, myelination is incomplete which may affect the EP $[8,12]$. Neurodevelopmental disorders in children may present with higher EP thresholds, possibly, due to neuronal atrophy and altered synaptogenesis $[52,53]$. Thus, neuromonitoring in pediatric patients requires experience of EP interpretation in this patient population.
Resection of the intramedullary spinal tumors is a high-risk procedure, and the most commonly used approach to such tumors is via dorsal median raphae. While electrical stimulation with subsequent recording of peripheral nerve or muscle responses is the standard approach, a newer technique with bipolar stimulation with subsequent SSEP recording has been suggested to identify the safe entry zone while approaching the tumor [54]. The safe incision zone is identified by characteristic phase-reversal of the EP. SSEP during upper cervical spine surgery may also detect brainstem ischemia caused by surgery [55].

SSEP and MEP have also been successfully used during syringomyelia surgery [56].

As a single monitoring modality, SSEP has a comparatively low sensitivity, and significant motor deficit may develop with preserved signal. On the other hand, intraoperative SSEP alerts may not be related with new neurological deficit in the postoperative period [57].

Combination of SSEP with MEP significantly improves the efficacy of monitoring [58]. Other fields of SSEP application include orthopedic, vascular surgery and procedures on peripheral nerves [59-64].

Spinal cord to scalp stimulation is an alternative although less commonly used method of SSEP monitoring [23].

A critical limitation of SSEP is the temporal summation, occasionally, requiring time intervals sufficient for permanent neurological damage [47]. Another inherent limitation is the low sensitivity in revealing isolated motor pathway injury [65]. Most of the studies reporting false-negative results with SSEP monitoring described insensibility of SSEP in cases of anterior spinal artery syndrome selectively affecting the antero-lateral column of spinal cord [23]. Any electrophysiological test will provide information only on specific neural structures and pathways propagating the signal, and there will always be clinical situations when local isolated damage to a region adjacent but functionally unrelated to the monitored pathway will remain unrecognized. Naturally, neither SSEP nor TcMEP are very good for predicting clinical deterioration in the opposite test's neurological counterpart [66].

MEP require more restrictive anesthesia requirements, may cause patient movements and have less clearly defined criteria for rais-

Figure 3. Somatosensory Evoked Potentials (SSEP) with stable right upper extremity responses and a decrement in the left upper extremity responses due to arm positioning (anesthesia: sevoflurane, remifentanil infusion). N20 (left mark), P23 (right mark).

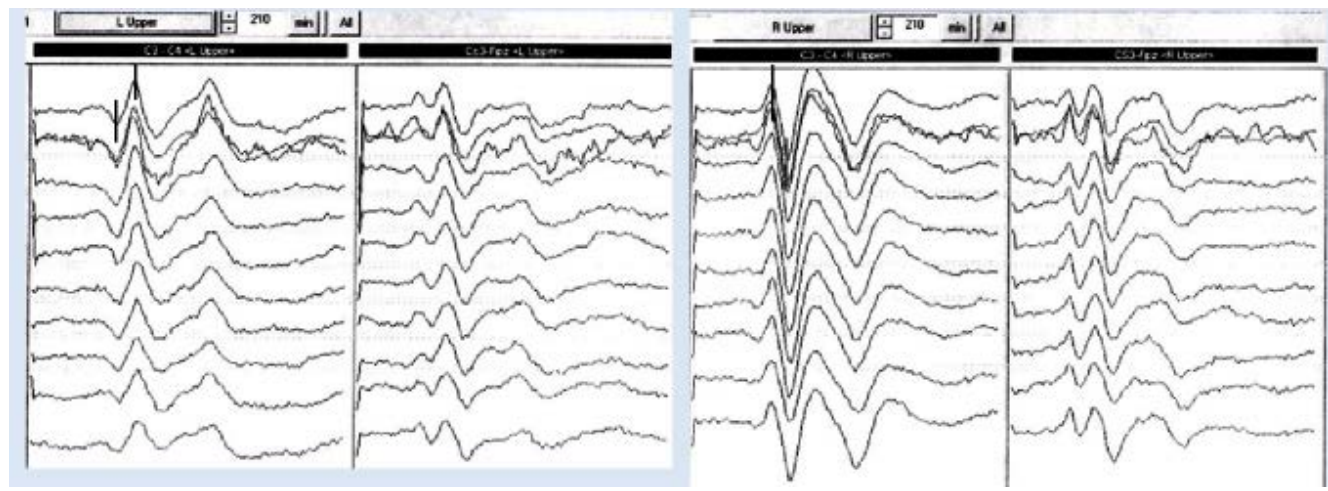


ing the alarm [48]. Nevertheless, MEP became a significant step towards safer and less traumatic surgery.

Merton and Morton (1980) were the first to describe transcranial electrical stimulation in humans $[67,23,47]$. Later on, application of high-frequency multi-pulse electrical stimulation with relatively low voltages improved the reproducibility of the method and, along with improvements in anesthesia protocols, led to widespread use of MEP during spinal surgery [47].

MEP can be evoked via transcranial or direct cortical stimulation. However, the noninvasive transcranial stimulation is the preferred method [15].

Numerous methods to monitor the motor pathways have been suggested: spinal cord to spinal cord technique, neurogenic and myogenic MEP, triggered and free-running EMG, recording the D- and I-waves and CMAP, which all have their indications, advantages and limitations [8, 20, 23, 47]. Among them, the most commonly used methods are D-wave registration using epidural or spinal electrodes and CMAP recorded from the muscles of interest. These methods can be applied separately or in combination with free-running EMG.

D-waves reflect direct activation of the corticospinal pathways and are used mainly during surgery on proximal (above $\mathrm{T}_{10}$ ) spinal cord $[68,47,15,23,69]$. A $20-50 \%$ decrease in D-wave amplitude or a $10 \%$ increase in latency is indicative of possible postoperative neurological deterioration [47, 70-72].

EMG recording of transcranial MEP (CMAP) allows for assessment of the entire motor pathway including the peripheral nerve. [47] During monitoring, muscle relaxants generally should be avoided and anesthesia levels kept stable, although some centers prefer partial muscle relaxation during surgery.

For TcMEP monitoring, muscle relaxants are used for intubation only, and if they still are to be used, a target $\mathrm{T}_{2} / \mathrm{T}_{\text {baseline }}$ of 0.5 is recommended $[43,73]$.

Muramoto et al. (2012) suggest using absolute and relative (to baseline) cutoff CMAP amplitudes $(12 \%, 1.9 \mu \mathrm{V}$ and $25 \%, 3.6 \mu \mathrm{V}$, respectively) as indicators of neurological deterioration [18]. Threshold stimulation level (increase of threshold stimulus $>100$ V) can be used as a criterion to detect intraoperative neurological deterioration ([66] as cited in [72]).

CMAP is more sensitive to ischemia than D-wave and SSEP, however, the D-wave amplitude correlates better with long-term motor outcome (as cited in [9]). A critical weakness of CMAP is the intermittent character of monitoring [47].

Adverse effects of TcMEP include cardio-vascular reactions, metabolic acidosis, tongue laceration, patient movements, and seizures [53]. TcMEP synchronization with ECG may help to avoid arrhythmias [63]. The possibility of false positive TcMEP should also be considered [74].

Triggered EMG is used to detect medial pedicle breach by a vertebral screw and is used in minimally invasive spinal surgery [15, 47, 72].

The main advantage of free-running EMG over the other meth- ods of motor pathway monitoring is continuous data acquisition [47]. The method is not specific and it is sensitive to changes in anesthesia and temperature, pre existing neurological deficit, electrical artifacts, and electrode positioning [8]. EMG combined with intermittent TcMEP has been suggested as a better way to monitor the motor pathways [75].

$\mathrm{H}$-reflexes and F-waves strongly depend on anesthesia level and are not currently considered part of a standard clinical practice [72].

\section{EP monitoring during surgery on the brain}

\section{VEP (CN II)}

The reported incidence of postoperative visual deterioration reaches $10 \%$ and varies from $3 \%$ to $38 \%$ among patients undergoing surgery for ophthalmic aneurysms, epilepsy and tumor resection in the vicinity of the optic tracts, chiasm and pituitary area $[76,77]$. Postoperative visual loss has been described even after spinal surgery $[58,78,79]$. VEP monitoring is indicated during surgery in vicinity of the visual pathways and during neurovascular procedures $[10,77,80]$. After initial enthusiasm, intraoperative VEP recording failed to show consistency with no clear development over decades of standard protocols for this monitoring technique (as cited in [81]).

Many literature reports show lack of correlation between the VEP and postoperative visual outcome attributable to preexisting visual dysfunction, technical difficulties as well as changes in anesthesia and physiological parameters [10, 11, 76, 82, 83].

The reproducibility of VEP during transsphenoidal surgery is $89.6 \%$, which is much lower than that for SSEP or BAEP [82].

Other reports indicate on usefulness of intraoperative VEP [9, $76,80,83,87$. Goto et al. (2007) reported of a patient with paraclinoid aneurysm where the superior hypophyseal artery (SHA) originated from the aneurysmal body [88]. During surgery, the VEP reversibly disappeared every time after attempts of SHA temporary clipping. Surgery was modified, and a permanent clip was placed on the aneurysm body sparing the SHA. The patient had no visual disturbance postoperatively.

Application of specially designed goggles and discs for stimulation, co-registration of electroretinogram, use of TIVA and other modifications help to overcome the technical obstacles and improve the diagnostic value of VEP $[80,83]$. Unfortunately, impaired preoperative vision is a major predictor of postoperative deterioration, and a strong dependence of VEP on intact vision constitutes a significant limitation [89].

Several authors used invasive methods of intraoperative visual evoked response registration with encouraging results [75, 84-87, 90-92].

Despite the controversies and conflicting results, recent advances in technology and anesthesia technique enhance the enthusiasm towards VEP and justify further research in this field.

\section{Olfactory EP (CN I)}

Anterior cranial fossa surgery is related to an increased risk of 
loss of the olfactory function $[77,93,94]$.

Anosmia may have a significant impact on quality of life, as depression and decrease in overall satisfaction with life have been associated with this complication [77]. Sato et al. (1996) proved experimentally and clinically the feasibility of intraoperative registration of stable and reproducible olfactory EP [94].

The method is not currently used in clinical practice, and requires further research.

\section{Rhomboid fossa mapping and CN monitoring}

Rhomboid fossa surgery requires high precision and carries the risk of serious trauma to vital structures [8, 95-98]. The brainstem contains vital centers, nuclei and pathways concentrated within a small volume, making surgery in this area extremely challenging. The situation becomes even more complex with distortion of normal anatomy by the growing tumor.

SSEP and BAEP together monitor only $20 \%$ of the brainstem (as cited in [98]) and, therefore, monitoring the motor function is important to increase the surgical safety and better control the extent of tumor resection.

Both mono-and bipolar and either constant-current or constantvoltage stimulation can be applied to locate the $\mathrm{CN}$ and their nuclei before tumor resection [95, 96, 99]. Stimulation intensity commonly starts at $2.0 \mathrm{~mA}$ and is reduced to the threshold level once the motor nucleus or $\mathrm{CN}$ is identified, or it can start at low levels and then progressively increased to elicit CMAP from the monitored muscle [98-100]. Stimulation of CN IX-X can evoke hypotension and bradycardia, while current intensities exceeding $2 \mathrm{~mA}$ may trigger cardiovascular reactions (as cited in [98, 99]).

For security reasons, the stimulation of any point should not exceed 5 seconds [97]. Negative stimulation results must not be interpreted as absence of $\mathrm{CN}$ nuclei under the probe. Instead, repetitive stimulation may be required through the tumor mass during resection in order to detect the $\mathrm{CN}$ nuclei [96].

Rhomboid fossa mapping monitors only the efferent pathways of the brainstem reflexes, and the patients may still develop bulbar dysfunction despite uneventful stimulation.
Monitoring the lower CN (IX-XII) during resection of low brainstem lesions is important to avoid associated atrophy of tongue muscles, dysphagia and loss of the cough reflex [11, 17, 95].

Evoked responses or free-running EMG can be registered using specially designed wire electrodes with 2-mm bare hook tips inserted into the soft palate or pharyngeal wall (CN IX), false vocal cords $(\mathrm{CN} \mathrm{X})$, lateral wall of intrinsic tongue muscle (CN XII), and trapezius muscle, (CN XI) or, alternatively, surface electrodes attached to a laryngeal mask or endotracheal tube may be used $[17,95,96,98,99,101,104]$.

Spontaneous EMG recorded from the false vocal cords can be used effectively to monitor the recurrent laryngeal nerve function during anterior cervical discectomy and fusion [105].

\section{Monitoring CN VII}

CN VII is frequently monitored during cerebellopontine angle (CPA) and rhomboid fossa surgery [11, 95, 97]. To monitor the facial nerve, EMG, observation, video-monitoring, CMAP, and MEP can be used.

High frequency $(>30 \mathrm{~Hz})$, high-amplitude $(100-200 \mu \mathrm{V})$ and long-lasting trains on facial EMG are related to worse postoperative facial nerve outcome [26].

An alternative or, perhaps, supplementary method to the intraoperative facial EMG registration is intraoperative direct observation or video-recording of the facial muscular activity [26].

Registration of CMAP following electrical stimulation of CN VII or the brainstem is a method of intermittent monitoring of the nerve integrity. To provide a real-time feedback to the surgeon, the evoked EMG signal triggers a sound alarm [26]. It is important to remember that CMAP registered after the intracranial stimulation will depend on stimulation intensity and allow for monitoring only the section from the stimulation site to the recording point, even though normal functioning of facial muscles requires integrity of the whole pathway [106-108]. Another limitation is the possibility of signal spread after facial nerve stimulation (Figure 4).

Intraoperative monitoring of facial MEP allows for monitoring

Figure 4. Electromyographic (EMG) responses to peripheral facial nerve stimulation with lateral spread before (A) and no lateral spread after (B) microvascular decompression in a patient undergoing surgery for hemifacial spasm on the left side (anesthesia: desflurane, remifentanil, propofol).

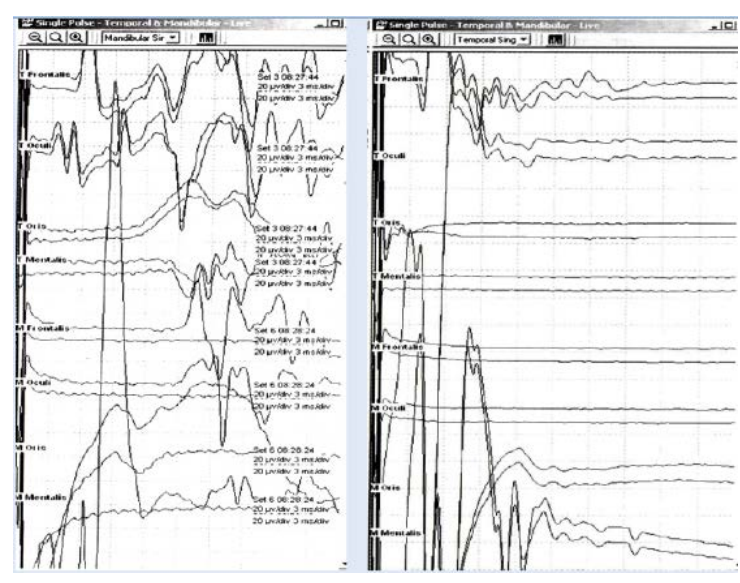


of the whole facial motor pathway [97]. A high correlation exists between the postoperative nerve function and final-to-baseline MEP ratio [106]. Initial contralateral single-pulse stimulation is recommended before recording the MEP to exclude any signal misinterpretation caused by direct electrical extracranial spread. $[100,106]$

\section{Monitoring CN V}

Cranial base and CPA procedures carry the risk of trigeminal nerve damage, and the incidence of de novo trigeminal symptoms following removal of cranial base meningiomas reaches $11 \%$ [109]. Consequences of intraoperative CN V damage include facial numbness, pain, decreased corneal sensitivity, disabled corneal reflexes, lacrimal dysfunction, hypersensitivity to light, cataracts, and corneal ulceration. Monitoring of $\mathrm{CN} \mathrm{V}$ can be accomplished by using a free-running EMG or CMAP (trapezius muscle) following intracranial stimulation. Despite the ability to identify the nerve intraoperatively, the methods' diagnostic value is questionable [110]. An alternative approach is monitoring the trigeminal SSEP [111, 112].

Blink reflexes are elicited by stimulation of the supraorbital branch of $\mathrm{CN} \mathrm{V}$, which induce a motor response in orbicular muscles consisting of a short-latency ipsilateral response (R1) of about $10 \mathrm{msec}$ followed by bilateral polysynaptic responses of longer latency $\left(\mathrm{R}_{2} \sim 30 \mathrm{msec}\right.$ and $\left.\mathrm{R}_{3} \sim 75-90 \mathrm{msec}\right)$ [113]. The blink reflexes are extremely sensitive to anesthesia, however, application of stimulation trains allows for monitoring the R1 response in patients under TIVA or light inhalational anesthesia [113, 114].

Intraoperative monitoring of the blink reflex may become a valuable tool in neurosurgery, but the method needs validation in a larger group of patients.

\section{Monitoring CN VIII}

BAEP are monitored during tumor removal at CPA, microvascular decompressions of CN VII and V (Figure 5), surgery on brainstem, and neurovascular interventions [5, 11, 97, 115-117]. BAEP are the least sensitive to changes in perioperative variables and drug actions [11]. However, conductive and sensorineural deafness on the surgery side preclude intraoperative BAEP monitoring.

The mechanisms of intraoperative acoustic nerve damage and hearing impairment are multiple and include cerebellar retraction with nerve stretching, direct mechanical trauma, electrical coagulation, high-energy electrical stimulation, and ischemia due to damage or vasospasm of the internal auditory artery $[11,26]$.

There are numerous studies showing improving hearing outcome with BAEP monitoring during acoustic neuroma surgery (as cited in $[9,11,118])$.

BAEP changes are assessed by comparing with the baseline recordings [16, 116]. Jahangiri et al. (2012) used the following criteria as warning signs during brainstem surgery: complete obliteration of peaks III and/or $\mathrm{V}$ and increase in peak $\mathrm{V}$ latency $>1 \mathrm{msec}$ [95]. Others recommend a 50\% decrease of peak amplitudes and $>0.5$ msec increase in wave $\mathrm{V}$ latency or even $20 \%$ changes in amplitudes and $0.1 \mathrm{msec}$ delay in latency $[16,116]$.

IPL are less susceptible to host-related variables like age, gender and stimulation intensity when compared with peak $\mathrm{V}$ absolute latency [116]. However, the majority of these parameters are, at best, warning signs that alert the surgeon; among them only maintenance of peaks I and V has been consistently shown to correlate with better postoperative hearing preservation rates, although others have found poor correlation between postoperative hearing and BAEP [26].

False-positive and false-negative results of BAEP monitoring are explained by anesthesia, hypothermia, ear problems, as well as surgical manipulations not involving the auditory pathways and nuclei $[16,26,115,119,118]$.

In contrast to BAEP, intraoperative ECoG and acoustic nerve CNAP record near-field potentials directly from the nerve, which ensures higher quality of signal and significant decrease in acquisition time [26]. While ECoG record the cochlear potential via transtympanic electrode, the CNAP are monitored directly from the acoustic nerve. In both cases, standard click stimulation is applied to generate the electrical potential.

Figure 5. Stable brainstem acoustic evoked potentials (BAEP) in a patient undergoing surgery for hemifacial spasm (anesthesia: desflurane, remifentanil, propofol). Waveforms I and V are marked on figure from left to right.

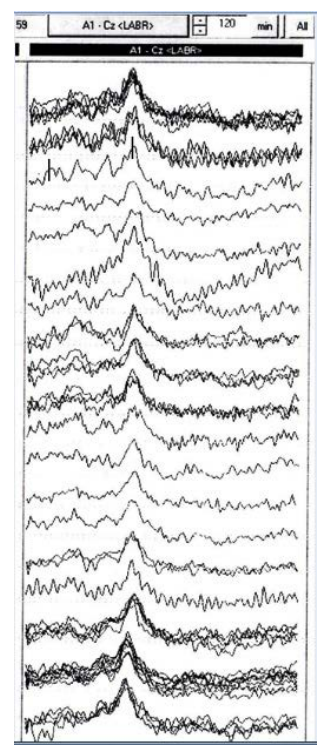


Thus, BAEP, ECoG and CNAP are valuable modalities which can help to preserve postoperative hearing and prevent irreversible damage to brainstem structures.

\section{Monitoring CN III, IV and VI}

The oculomotor, trochlear and abducens nerves are predominantly motor nerves with a few proprioceptive afferents terminating in the mesencephalic nucleus of CN V [120]. Intraoperative damage to these nerves will cause diplopia and seriously affect the lifestyle [120]. Both free-running EMG and CMAP after intracranial stimulation are used to monitor the oculomotor function and find a safe entry zone to the tegmental lesions $[98,121]$.

Electrooculography (EOG) is based on registration of the corneo-retinal electrical potential projected on the tissues surrounding the eye $[120,122,123]$. Eye movements cause orientation changes of the corneo-retinal potential thus allowing for monitoring spontaneous eye movements during surgery. In contrast to EMG, the method is noninvasive, and surface plate electrodes can be used to record the vertical and horizontal eye movements on separate channels. High amplitude $(>300 \mathrm{mcV})$ waves and trains of waves correlate with intraoperative tissue damage in the midbrain region, while small amplitude waves $(50-150 \mathrm{mcV}$ ) and trains indicate possible trauma to the ponto-medullary area. EOG is not diagnostic for CPA pathology due to artifacts induced by irritation of the facial nerve [123].

A limitation of EOG is susceptibility to artifacts generated by electrical coagulation and stimulation.

\section{SSEP and MEP monitoring during brain surgery}

SSEP are sensitive to changes in cerebral blood flow (CBF), although signal changes appear more slowly compared with EEG. $[6,9,118]$. In contrast to SSEP, EEG does not require averaging, covers larger cortical areas and is more sensitive to ischemia. However, SSEP is more specific and can detect ischemia in deeper structures including the brainstem. Unilateral SSEP changes on the side of surgery allow for differentiating between local ischemia caused by arterial clamping and global CBF derangement [124]. Combination of SSEP with MEP reduces the incidence of false-negative responses during carotid endarterectomy and helps to determine indications for temporary shunting $[125,126]$.

On the other hand, co-registration of SSEP with BAEP is $86 \%$ sensitive and $98 \%$ specific in predicting the neurological deficit during resection of cerebral AVM [115].

Surgery on cerebral aneurysms carries the risk of intraoperative ischemia in 5\% of cases. (as cited in [19]) SSEP changes correlate with intraoperative $\mathrm{CBF}$ reduction, which makes that modality a valuable monitoring method during aneurysm surgery.According to Kang et al. (2013), SSEP monitoring is indicated when the aneurysms are supplied by internal carotid, anterior, middle, and posterior cerebral arteries [19]. Simultaneous BAEP recording may be required during posterior circulation surgery, even thoughthis combination yields an unacceptably high false-negative rate of $25 \%$ during basilar artery surgery (as cited in [127]). Accidental clamping of small perforator arteries during basilar aneurysm surgery may result in infarctions involving the thalamus, internal capsule, and midbrain, with resultant alterations in consciousness, hemiparesis or hemiplegia in the postoperative period. In such patients, combination of SSEP with TcMEP will improve the safety and increase the efficacy of INM [128].

Surgery in the territory of anterior cerebral arteries places at risk cortical areas controlling the lower extremities. In these cases, lower extremity SSEP is indicated, [9] while median nerve SSEP is the method of choice for aneurysms supplied by the middle cerebral and carotid arteries.

Significant SSEP changes during aneurysm surgery occur in $6.5 \%$ of cases [127]. Irreversible changes carry an $80 \%$ risk of postoperative stroke in patients with unruptured aneurysms, while the risk is $20 \%$ with reversible SSEP changes [127].

Intraoperative pneumocephalus, especially during sitting craniotomies, may significantly impact the SSEP registration [16, 129]. Multimodal neuromonitoring, which includes SSEP, direct electrical stimulation and MEP, has become an essential component during surgery in highly eloquent areas including cortical zones of language and motor control as well as deep-seated gliomas [3, $5,95,130-138]$.

During such interventions, ischemic events are the major source of permanent postoperative motor dysfunction, whereas, parenchymal resection represents a minor reason for neurological consequences [139]. A new motor deficit may be reversible if MEP recovery is achieved by early signs and appropriate modifications are made in the surgical procedure [110]. SSEP and MEP monitor distinct neuronal pathways, and both methods may be considered supplementary.

\section{Conclusion}

Evoked responses are a valuable mode of INM. The selection of specific EP depends on location of the lesion, preexisting pathology, clinical experience with the method, and other factors. Sensitivity of the signal to general anesthetics and changes in physiological parameters during surgery must be taken into account. Advancements in INM technologies, neurosurgical technique and anesthesia significantly improve the quality and efficacy of neurosurgical procedures, reduce morbidity and improve the neurological outcome. Several above described methods still are not commonly used, and further research is required before their widespread application in clinical practice.

An active interaction between anesthesiologists, neurosurgeons and the neurophysiology team working in the operating room is a prerequisite for successful intraoperative EP monitoring and timely interpretation of the data.

\section{Acknowledgements}

The authors would like to thank Andrei M. Jipa, medical student from the University of Cincinnati College of Medicine, for his active participation in preparation of the manuscript.

\section{References}

[1]. Bonhomme V, Franssen C, Hans P (2009) Awake craniotomy. Eur J Anaesthesiol 26(11):906-912.

[2]. Grottke O, Dietrich PJ, Wiegels S, Wappler F (2004) Intraoperative wakeup test and postoperative emergence in patients undergoing spinal surgery: 
a comparison of intravenous and inhaled anesthetic techniques using shortacting anesthetics. Anesth Analg 99(5):1521-1527.

[3]. Krieg SM, Schnurbus L, Shiban E, Droese D, Obermueller T, et al. (2013) Surgery of highly eloquent gliomas primarily assessed as non-resectable: risks and benefits in a cohort study. BMC Cancer 13(1):51.

[4]. Lu J, Wu J, Yao C, Zhuang D, Qiu T, et al. (2013) Awake language mapping and 3-Tesla intraoperative MRI-guided volumetric resection for gliomas in language areas. J Clin Neurosci 20(9):1280-1287.

[5]. Ng WH, Mukhida K, Rutka JT (2010) Image guidance and neuromonitoring in neurosurgery. Childs Nerv Syst 26(4):491-502.

[6]. Florence G, Guerit JM, Gueguen B (2004) Electroencephalography (EEG) and somatosensory evoked potentials (SEP) to prevent cerebral ischaemia in the operating room. Neurophysiol Clin 34(1):17-32.

[7]. Freye E, Levy JV (2005) Cerebral monitoring in the operating room and the intensive care unit: an introductory for the clinician and a guide for the novice wanting to open a window to the brain. Part I: The electroencephalogram. J Clin Monit Comput 19(1-2):1-76.

[8]. Galloway GM, Zamel K (2011) Neurophysiologic intraoperative monitoring in pediatrics. Pediatr Neurol 44(3):161-170.

[9]. Jameson LC, Sloan TB (2012) Neurophysiologic monitoring in neurosurgery. Anesthesiol Clin 30(2):311-331.

[10]. Banoub M, Tetzlaff JE, Schubert A (2003) Pharmacologic and physiologic influences affecting sensory evoked potentials: implications for perioperative monitoring. Anesthesiology 99(3):716-737.

[11]. Kumar A, Bhattacharya A, Makhija N (2000) Evoked potential monitoring in anaesthesia and analgesia. Anaesthesia 55(3):225-241.

[12]. Freye E (2005) Cerebral monitoring in the operating room and the intensive care unit - an introductory for the clinician and a guide for the novice wanting to open a window to the brain. Part II: Sensory-evoked potentials (SSEP, AEP, VEP). J Clin Monit Comput 19(1-2):77-168.

[13]. Møller A (2011) Intraoperative Neurophysiological Monitoring. Springer, New York.

[14]. Symon L, Hargadine J, Zawirski M, Branston N (1979) Central conduction time as an index of ischaemia in subarachnoid haemorrhage. J Neurol Sci 44(1):95-103

[15]. Deletis V (2007) Basic methodological principles of multimodal intraoperative monitoring during spine surgeries. Eur Spine J 16 Suppl 2:S147-152.

[16]. Shchekut'ev GA, Lubnin A, Barkalaia DE, Sogomonian SA (1994) [Monitoring of short latent evoked potentials during brain stem surgery]. Anesteziol Reanimatol (5):48-52.

[17]. Topsakal C, Al-Mefty O, Bulsara KR, Williford VS (2008) Intraoperative monitoring of lower cranial nerves in skull base surgery: technical report and review of 123 monitored cases. Neurosurg Rev 31(1):45-53.

[18]. Muramoto A, Imagama S, Ito Z, Wakao N, Ando K, et al. (2013) The cutoff amplitude of transcranial motor-evoked potentials for predicting postoperative motor deficits in thoracic spine surgery. Spine 38(1):E21-27.

[19]. Kang D, Yao P, Wu Z, Yu L (2013) Ischemia changes and tolerance ratio of evoked potential monitoring in intracranial aneurysm surgery. Clin Neurol Neurosurg 115 (5):552-556.

[20]. Raynor BL, Bright JD, Lenke LG, Rahman RK, Bridwell KH, et al. (2013) Significant change or loss of intraoperative monitoring data: a 25-year experience in 12,375 spinal surgeries. Spine 38 (2):E101-108

[21]. Gavaret M, Jouve JL, Pereon Y, Accadbled F, Andre-Obadia N, et al. (2013) Intraoperative neurophysiologic monitoring in spine surgery. Developments and state of the art in France in 2011. OrthopTraumatol Surg Res $99(6$ Suppl):S319-327.

[22]. Bouwes A, Doesborg PG, Laman DM, Koelman JH, Imanse JG, et al. (2013) Hypothermia after CPR prolongs conduction times of somatosensory evoked potentials. Neurocrit Care 19(1):25-30.

[23]. Deletis V, Sala F (2008) Intraoperative neurophysiological monitoring of the spinal cord during spinal cord and spine surgery: a review focus on the corticospinal tracts. Clin Neurophysiol 119(2):248-264.

[24]. Daroff R, Fenichel, G, Jankovic, Mazziota, J (2012) Clinical Neurophysiology: EEG and EPs. In Neurology in Clinical Practice. (6th edtn), Elsevier, Philadelphia.

[25]. Krieg SM, Shiban E, Droese D, Gempt J, Buchmann N, et al. (2012) Predictive value and safety of intraoperative neurophysiological monitoring with motor evoked potentials in glioma surgery. Neurosurgery 70(5):10601070 .

[26]. Oh T, Nagasawa DT, Fong BM, Trang A, Gopen Q, et al. (2012) Intraoperative neuromonitoring techniques in the surgical management of acoustic neuromas. Neurosurg Focus 33(3):E6.

[27]. Feuerecker M, Lenk M, Flake G, Edelmann-Gahr V, Wiepcke D, et al. (2011) Effects of increasing sevoflurane MAC levels on mid-latency auditory evoked potentials in infants, schoolchildren, and the elderly. $\mathrm{Br} \mathrm{J}$ Anaesth 107(5):726-734

[28]. Untergehrer G, Jordan D, Eyl S, Schneider G (2013) Effects of propofol, sevoflurane, remifentanil, and (S)-ketamine in subanesthetic concentra- tions on visceral and somatosensory pain-evoked potentials. Anesthesiology 118(2):308-317.

[29]. Lotto ML, Banoub M, Schubert A (2004) Effects of anesthetic agents and physiologic changes on intraoperative motor evoked potentials. J Neurosurg Anesthesiol 16(1):32-42.

[30]. Sloan TB (2012) General Anesthesia for Monitoring. In: Koht A ST, and Toleikis JR (ed) Monitoring the Nervous System for Anesthesiologists and Other Health Care Professionals. Springer Science+Business Media, New York. 319-335.

[31]. Soghomonyan S, Moran KR, Sandhu GS, Bergese SD (2014) Anesthesia and evoked responses in neurosurgery. Front Pharmacol 5:74.

[32]. Lo YL, Dan YF, Tan YE, Nurjannah S, Tan SB, et al. (2004) Intra-operative monitoring in scoliosis surgery with multi-pulse cortical stimuli and desflurane anesthesia. Spinal Cord 42(6):342-345.

[33]. Lo YL, Dan YF, Tan YE, Nurjannah S, Tan SB, et al. (2006) Intraoperative motor-evoked potential monitoring in scoliosis surgery: comparison of desflurane/nitrous oxide with propofol total intravenous anesthetic regimens. J Neurosurg Anesthesiol 18(3):211-214.

[34]. Kempton LB, Nantau WE, Zaltz I (2010) Successful monitoring of transcranial electrical motor evoked potentials with isoflurane and nitrous oxide in scoliosis surgeries. Spine 35(26):E1627-1629.

[35]. Fulkerson DH, Satyan KB, Wilder LM, Riviello JJ, Stayer SA, et al. (2011) Intraoperative monitoring of motor evoked potentials in very young children. J Neurosurg Pediatr 7(4):331-337.

[36]. Asouhidou I, Katsaridis V, Vaidis G, Ioannou P, Givissis P, et al. (2010) Somatosensory Evoked Potentials suppression due to remifentanil during spinal operations; a prospective clinical study. Scoliosis 5:8.

[37]. Yang J, Huang Z, Shu H, Chen Y, Sun X, et al. (2012) Improving successful rate of transcranial electrical motor-evoked potentials monitoring during spinal surgery in young children. Eur Spine J 21(5):980-984.

[38]. Tobias JD, Goble TJ, Bates G, Anderson JT, Hoernschemeyer DG (2008) Effects of dexmedetomidine on intraoperative motor and somatosensory evoked potential monitoring during spinal surgery in adolescents. Paediatr Anaesth 18(11):1082-1088.

[39]. Penney R (2010) Use of dexmedetomidine and ketamine infusions during scoliosis repair surgery with somatosensory and motor-evoked potential monitoring: a case report. AANA J 78(6):446-450.

[40]. Sloan TB, Mongan P, Lyda C, Koht A (2013) Lidocaine infusion adjunct to total intravenous anesthesia reduces the total dose of propofol during intraoperative neurophysiological monitoring. J Clin Monit Comput 28(2):139147.

[41]. Pajewski TN, Arlet V, Phillips LH (2007) Current approach on spinal cord monitoring: the point of view of the neurologist, the anesthesiologist and the spine surgeon. Eur Spine J 16 Suppl 2:S115-129.

[42]. Kunisawa T, Nagata O, Nomura M, Iwasaki H, Ozaki M (2004) A comparison of the absolute amplitude of motor evoked potentials among groups of patients with various concentrations of nitrous oxide. J Anesth 18(3):181184.

[43]. Kim WH, Lee JJ, Lee SM, Park MN, Park SK, et al. (2013) Comparison of motor-evoked potentials monitoring in response to transcranial electrical stimulation in subjects undergoing neurosurgery with partial vs no neuromuscular block. Br J Anaesth 110(4):567-576.

[44]. van Dongen EP, ter Beek HT, Schepens MA, Morshuis WJ, Langemeijer HJ, et al. (1999) Within-patient variability of myogenic motor-evoked potentials to multipulse transcranial electrical stimulation during two levels of partial neuromuscular blockade in aortic surgery. Anesth Analg 88(1):2227.

[45]. Deipolyi AR, Han SJ, Sughrue ME, Litt L, Parsa AT (2011) Awake far lateral craniotomy for resection of foramen magnum meningioma in a patient with tenuous motor and somatosensory evoked potentials. J Clin Neurosci 18(9):1254-1256

[46]. Lyon R, Feiner J, Lieberman JA (2005) Progressive suppression of motor evoked potentials during general anesthesia: the phenomenon of "anesthetic fade". J Neurosurg Anesthesiol 17(1):13-19.

[47]. Lall RR, Lall RR, Hauptman JS, Munoz C, Cybulski GR, et al. (2012) Intraoperative neurophysiological monitoring in spine surgery: indications, efficacy, and role of the preoperative checklist. Neurosurg Focus 33(5):E10.

[48]. Nuwer MR, Emerson RG, Galloway G, Legatt AD, Lopez J, et al. (2012) Evidence-based guideline update: intraoperative spinal monitoring with somatosensory and transcranial electrical motor evoked potentials. J Clin Neurophysiol 29(1):101-108.

[49]. Li N, Tian L, Wu W, Lu H, Zhou Y, et al. (2013) Regional hypothermia inhibits spinal cord somatosensory-evoked potentials without neural damage in uninjured rats. J Neurotrauma 30(15):1325-1333.

[50]. Mohammdi A, Fard AJ, Dalvandi M (2012) Intraoperative neurophysiological monitoring in spinal root surgical interventions. J Inj Viol Res 4(3 suppl 1):8.

[51]. Houlden DA, Ubriaco G, Stewart CP, Robertson SL, Cohen M, et al. 
(2012) Optimal intraoperative somatosensory evoked potential stimulus intensity can be determined by nerve action potential amplitude. J ClinNeurophysiol 29(6):509-513.

[52]. Lieberman JA, Lyon R, Feiner J, Diab M, Gregory GA (2006) The effect of age on motor evoked potentials in children under propofol/isoflurane anesthesia. Anesth Analg 103(2):316-321.

[53]. Patel AJ, Agadi S, Thomas JG, Schmidt RJ, Hwang SW, et al. (2013) Neurophysiologic intraoperative monitoring in children with Down syndrome. Childs Nerv Syst 29(2):281-287.

[54]. Simon MV, Chiappa KH, Borges LF (2012) Phase reversal of somatosensory evoked potentials triggered by gracilis tract stimulation: case report of a new technique for neurophysiologic dorsal column mapping. Neurosurgery 70(3):E783-788.

[55]. Tran CT, Khoo LT, Martin NA, Fong SS, Nuwer MR (2012) Somatosensory-evoked potential asymmetry in medullary ischemia during cervical spine surgery. J Clin Neurophysiol 29(1):17-22.

[56]. Pencovich N, Korn A, Constantini S (2013) Intraoperative neurophysiologic monitoring during syringomyelia surgery: lessons from a series of 13 patients. Acta Neurochir (Wien) 155(5):785-791.

[57]. Yaylali I, Ju H, Yoo J, Ching A, Hart R (2014) Intraoperative neurophysiological monitoring in anterior lumbar interbody fusion surgery. J Clin Neurophysiol 31(4):352-355.

[58]. Li F, Gorji R, Allott G, Modes K, Lunn R, et al. (2012) The usefulness of intraoperative neurophysiological monitoring in cervical spine surgery: a retrospective analysis of 200 consecutive patients. J Neurosurg Anesthesiol 24(3):185-190.

[59]. Haghighi SS, Richard Z, Ramirez B (2013) Somatosensory-evoked potential monitoring detects iliac artery occlusion during posterior spinal fusion. Spine 38(7):E436-439.

[60]. Ochs BC, Herzka A, Yaylali I (2012) Intraoperative neurophysiological monitoring of somatosensory evoked potentials during hip arthroscopy surgery. Neurodiag J 52(4):312-319.

[61]. McGarvey ML (2012) Effective tool or necessary evil: intraoperative monitoring during thoracic aneurysm repairs. J Clin Neurophysiol 29(2):154156.

[62]. Schurink GW, De Haan MW, Peppelenbosch AG, Mess W, Jacobs MJ (2013) Spinal cord function monitoring during endovascular treatment of thoracoabdominal aneurysms: implications for staged procedures. J Cardiovasc Surg 54(1 Suppl 1):117-124.

[63]. ter Wolbeek C, Hartert M, Conzelmann LO, Peivandi AA, Czerny M, et al. (2010) Value and pitfalls of neurophysiological monitoring in thoracic and thoracoabdominal aortic replacement and endovascular repair. Thorac Cardiovasc Surg 58(5):260-264.

[64]. Weigang E, Hartert M, Siegenthaler MP, Pitzer-Hartert K, Luehr M, et al. (2006) Neurophysiological monitoring during thoracoabdominal aortic endovascular stent graft implantation. Eur J Cardiothorac Surg 29(3):392396.

[65]. Kim SM, Kim SH, Seo DW, Lee KW (2013) Intraoperative neurophysiologic monitoring: basic principles and recent update. J Korean Med Sci 28(9):1261-1269.

[66]. Calancie B, Harris W, Broton JG, Alexeeva N, Green BA (1998) "Threshold-level" multipulse transcranial electrical stimulation of motor cortex for intraoperative monitoring of spinal motor tracts: description of method and comparison to somatosensory evoked potential monitoring. J Neurosurg 88(3):457-470.

[67]. Awad BI, Carmody MA, Zhang X, Lin VW, Steinmetz MP (2013) Transcranial Magnetic Stimulation After Spinal Cord Injury. World Neurosurg.

[68]. Eicker SO, Szelenyi A, Mathys C, Steiger HJ, Hanggi D (2013) Customtailored minimally invasive partial C2-corpectomy for ventrally located intramedullary cavernous malformation. Neurosurg Rev 36(3):487-491.

[69]. Macdonald DB, Skinner S, Shils J, Yingling C (2013) Intraoperative motor evoked potential monitoring - A position statement by the American Society of Neurophysiological Monitoring. Clin Neurophysiol 124(12):2291-2316.

[70]. Yamamoto T FC, Katayama Y. (2011) Monitoring Neurosurgical Procedure Using D Wave Technique-Nihon University Experience. http://neuromonitoring.files.wordpress.com/2011/03/dwave.pdf.

[71]. Ito Z, Imagama S, Sakai Y, Katayama Y, Wakao N, et al. (2012) A new criterion for the alarm point for compound muscle action potentials. J Neurosurg Spine 17(4):348-356

[72]. Stecker MM (2012) A review of intraoperative monitoring for spinal surgery. Surg Neurol Int 3(Suppl 3):S174-187.

[73]. Hemmer LB, Zeeni C, Bebawy JF, Bendok BR, Cotton MA, et al. (2012) The Incidence of Unacceptable Movement with Motor Evoked Potentials During Craniotomy for Aneurysm Clipping. World Neurosurg.

[74]. Kim DH, Zaremski J, Kwon B, Jenis L, Woodard E, et al. (2007) Risk factors for false positive transcranial motor evoked potential monitoring alerts during surgical treatment of cervical myelopathy. Spine 32(26):3041-3046.

[75]. Fotakopoulos G, Alexiou GA, Pachatouridis D, Karagiorgiadis D, Konit- siotis S, et al. (2013) The value of transcranial motor-evoked potentials and free-running electromyography in surgery for cervical disc herniation. J Clin Neurosci 20(2):263-266.

[76]. Benedicic M, Bosnjak R (2011) Intraoperative monitoring of the visual function using cortical potentials after electrical epidural stimulation of the optic nerve. Acta Neurochir (Wien) 153(10):1919-1927.

[77]. Thirumala PD, Habeych ME, Crammond DJ, Balzer JR (2011) Neurophysiologic intraoperative monitoring of olfactory and optic nerves. J Clin Neurophysiol 28(6):538-542.

[78]. Kabbara AI (2007) What happened to the old visual evoked potential monitoring? Anesthesiology 106(6):1249.

[79]. Uribe AA, Baig MN, Puente EG, Viloria A, Mendel E, et al. (2012) Current intraoperative devices to reduce visual loss after spine surgery. Neurosurg Focus 33(2):E14.

[80]. Kodama K, Goto T, Sato A, Sakai K, Tanaka Y, et al. (2010) Standard and limitation of intraoperative monitoring of the visual evoked potential. Acta Neurochir (Wien) 152(4):643-648.

[81]. Cohen BA, Baldwin ME (2011) Visual-evoked potentials for intraoperative neurophysiology monitoring: another flash in the pan? J Clin Neurophysiol 28(6):599-601.

[82]. Chung SB, Park CW, Seo DW, Kong DS, Park SK (2012) Intraoperative visual evoked potential has no association with postoperative visual outcomes in transsphenoidal surgery. Acta Neurochir (Wien) 154(8):15051510

[83]. Sasaki T, Itakura T, Suzuki K, Kasuya H, Munakata R, et al. (2010) Intraoperative monitoring of visual evoked potential: introduction of a clinically useful method. J Neurosurg 112(2):273-284.

[84]. Benedicic M, Bosnjak R (2011) Optic nerve potentials and cortical potentials after stimulation of the anterior visual pathway during neurosurgery. Doc Ophthalmol 122(2):115-125.

[85]. Bosnjak R, Benedicic M (2008) Direct epidural electrical stimulation of the optic nerve: a new method for intraoperative assessment of function. J Neurosurg 109(4):647-653.

[86]. Landi A, Pirillo D, Cilia R, Antonini A, Sganzerla EP (2011) Cortical visual evoked potentials recorded after optic tract near field stimulation during GPi-DBS in non-cooperative patients. Clin Neurol Neurosurg 113(2):119122.

[87]. Ota T, Kawai K, Kamada K, Kin T, Saito N (2010) Intraoperative monitoring of cortically recorded visual response for posterior visual pathway. J Neurosurg 112(2):285-294.

[88]. Goto T, Tanaka Y, Kodama K, Kusano Y, Sakai K, et al. (2007) Loss of visual evoked potential following temporary occlusion of the superior hypophyseal artery during aneurysm clip placement surgery. Case report. J Neurosurg 107(4):865-867.

[89]. Neuloh G (2010) Time to revisit VEP monitoring? Acta Neurochir (Wien) 152(4):649-650.

[90]. Curatolo JM, Macdonell RA, Berkovic SF, Fabinyi GC (2000) Intraoperative monitoring to preserve central visual fields during occipital corticectomy for epilepsy. J Clin Neurosci 7(3):234-237.

[91]. Kikuchi Y, Sasaki T, Matsumoto M, Oikawa T, Itakura T, et al. (2005) Optic nerve evoked potentials elicited by electrical stimulation. Neurol Med Chir (Tokyo) 45(7):349-355.

[92]. San-Juan D, de Dios Del Castillo Calcaneo J, Villegas TG, Elizondo DL, Torrontegui JA, et al. (2011) Visual intraoperative monitoring of occipital arteriovenous malformation surgery. Clin Neurol Neurosurg 113(8):680682.

[93]. Park J, Lee SH, Kang DH, Kim JS (2009) Olfactory dysfunction after ipsilateral and contralateral pterional approaches for cerebral aneurysms. Neurosurgery $65(4): 727-732$.

[94]. Sato M, Kodama N, Sasaki T, Ohta M (1996) Olfactory evoked potentials: experimental and clinical studies. J Neurosurg 85(6):1122-1126.

[95]. Jahangiri FR, Minhas M, Jane J Jr. (2012) Preventing lower cranial nerve injuries during fourth ventricle tumor resection by utilizing intraoperative neurophysiological monitoring. Neurodiagn J 52(4):320-332.

[96]. Morota N, Deletis V (2006) The importance of brainstem mapping in brainstem surgical anatomy before the fourth ventricle and implication for intraoperative neurophysiological mapping. Acta Neurochir (Wien) 148(5):499-509.

[97]. Morota N, Ihara S, Deletis V (2010) Intraoperative neurophysiology for surgery in and around the brainstem: role of brainstem mapping and corticobulbar tract motor-evoked potential monitoring. Childs Nerv Syst 26(4):513-521.

[98]. Sala F, Manganotti P, Tramontano V, Bricolo A, Gerosa M (2007) Monitoring of motor pathways during brain stem surgery: what we have achieved and what we still miss? Neurophysiol Clin 37(6):399-406.

[99]. Singh R, Husain AM (2011) Neurophysiologic intraoperative monitoring of the glossopharyngeal and vagus nerves. J Clin Neurophysiol 28(6):582586. 
[100].Sarnthein J, Hejrati N, Neidert MC, Huber AM, Krayenbuhl N (2013) Facial nerve motor evoked potentials during skull base surgery to monitor facial nerve function using the threshold-level method. Neurosurg Focus 34(3):E7.

[101]. Fukuda M, Takao T, Hiraishi T, Yajima N, Saito A, et al. (2013) Novel devices for intraoperative monitoring of glossopharyngeal and vagus nerves during skull base surgery. Surg Neurol Int 4:97.

[102]. Holdefer RN, Kinney GA, Robinson LR, Slimp JC (2013) Alternative sites for intraoperative monitoring of cranial nerves X and XII during intracranial surgeries. J Clinical Neurophysiol 30(3):275-279.

[103]. Husain AM, Wright DR, Stolp BW, Friedman AH, Keifer JC (2008) Neurophysiological intraoperative monitoring of the glossopharyngeal nerve: technical case report. Neurosurgery 63(4 Suppl 2):277-278.

[104]. Ito E, Ichikawa M, Itakura T, Ando H, Matsumoto Y, et al. (2013) Motor evoked potential monitoring of the vagus nerve with transcranial electrical stimulation during skull base surgeries. J Neurosurg 118(1):195-201.

[105].Dimopoulos VG, Chung I, Lee GP, Johnston KW, Kapsalakis IZ, et al. (2009) Quantitative estimation of the recurrent laryngeal nerve irritation by employing spontaneous intraoperative electromyographic monitoring during anterior cervical discectomy and fusion. J Spinal Disord Tech 22(1):1-7.

[106]. Akagami R, Dong CC, Westerberg BD (2005) Localized transcranial electrical motor evoked potentials for monitoring cranial nerves in cranial base surgery. Neurosurgery $57(1$ Suppl):78-85.

[107].Liu BY, Tian YJ, Liu W, Liu SL, Qiao H, et al. (2007) Intraoperative facial motor evoked potentials monitoring with transcranial electrical stimulation for preservation of facial nerve function in patients with large acoustic neuroma. Chin Med J (Engl) 120(4):323-325

[108]. Paradiso GO, Cunic DI, Gunraj CA, Chen R (2005) Representation of facial muscles in human motor cortex. J Physiol 567(Pt 1):323-336.

[109]. Westerlund U, Linderoth B, Mathiesen T (2012) Trigeminal complications arising after surgery of cranial base meningiomas. Neurosurg Rev 35(2):203-209.

[110]. Son BC, Lee SW, Kim S, Hong JT, Sung JH, et al. (2012) Transzygomatic approach with intraoperative neuromonitoring for resection of middle cranial fossa tumors. J Neurol Surg B Skull Base 73(1):28-35.

[111]. Malcharek MJ, Landgraf J, Hennig G, Sorge O, Aschermann J, et al. (2011) Recordings of long-latency trigeminal somatosensory-evoked potentials in patients under general anaesthesia. Clin Neurophysiol 122(5):1048-1054.

[112]. Naderi S, Matthies C, Samii M (2001) Trigeminal root recording in normal trigeminal function. Neurosurg Rev 24(2-3):93-96.

[113]. Mourisse J, Lerou J, Struys M, Zwarts M, Booij L (2007) Multi-level approach to anaesthetic effects produced by sevoflurane or propofol in humans: 1. BIS and blink reflex. Br J Anaesth 98(6):737-745.

[114]. Deletis V, Urriza J, Ulkatan S, Fernandez-Conejero I, Lesser J, et al. (2009) The feasibility of recording blink reflexes under general anesthesia. Muscle Nerve 39(5):642-646.

[115]. Chang SD, Lopez JR, Steinberg GK (1999) The usefulness of electrophysiological monitoring during resection of central nervous system vascular malformations. J Stroke Cerebrovasc Dis 8(6):412-422.

[116]. Thirumala PD, Ilangovan P, Habeych M, Crammond DJ, Balzer J (2013) Analysis of interpeak latencies of brainstem auditory evoked potential waveforms during microvascular decompression of cranial nerve VII for hemifacial spasm. Neurosurg Focus 34(3):E6.

[117]. Ying T, Thirumala P, Shah A, Nikonow T, Wichman K, et al. (2013) Incidence of high-frequency hearing loss after microvascular decompression for hemifacial spasm. J Neurosurg 118(4):719-724.

[118]. Thirumala PD, Kodavatiganti HS, Habeych M, Wichman K, Chang YF, et al. (2013) Value of multimodality monitoring using brainstem auditory evoked potentials and somatosensory evoked potentials in endoscopic endonasal surgery. Neurol Res 35(6):622-630.

[119]. Stone JL, Fino J, Patel K, Calderon-Arnulphi M, Suss N, et al. (2012) Modified brain stem auditory evoked potentials in patients with intracranial mass lesions. Clin EEG Neurosci 43(4):291-302.

[120].Lopez JR (2011) Neurophysiologic intraoperative monitoring of the oculomotor, trochlear, and abducens nerves. J Clin Neurophysiol 28(6):543-550.

[121]. Gao D, Fei Z, Jiang X, Zhang X, Liu W, et al. (2012) The microsurgical treatment of cranio-orbital tumors assisted by intraoperative electrophysio- logic monitoring and neuronavigation. Clin Neurol Neurosurg 114(7):891896.

[122]. Kawamata T, Ishii N, Amano K, Namioka T, Hori T, et al. (2013) A novel simple real-time electrooculographic monitoring system during transsphenoidal surgeries to prevent postoperative extraocular motor nerve dysfunction. Neurosurg Rev 36(3):371-376.

[123]. Sogomonian SA, Shchekut'ev GA, Luk'ianov VI, Lubnin A (1996) [Monitoring of eye movements in surgery of the brain stem and parastem structures]. Anesteziol Reanimatol (2):44-46.

[124]. Malek BN, Mohrhaus CA, Sheth AK (2011) Use of multi-modality intraoperative monitoring during carotid endarterectomy surgery: a case study. Am J Electroneurodiagnostic Technol 51(1):42-53.

[125]. Malcharek MJ, Ulkatan S, Marino V, Geyer M, Llado-Carbo E, et al. (2013) Intraoperative monitoring of carotid endarterectomy by transcranial motor evoked potential: a multicenter study of 600 patients. Clin Neurophysiol 124(5):1025-1030.

[126]. Malcharek MJ, Kulpok A, Deletis V, Ulkatan S, Sablotzki A, et al. (2014) Intraoperative Multimodal evoked potential monitoring during Carotid Endarterectomy: A Retrospective Study of 264 Patients. Anesth Analg 120(6):1352-1360.

[127]. Wicks RT, Pradilla G, Raza SM, Hadelsberg U, Coon AL, et al. (2012) Impact of changes in intraoperative somatosensory evoked potentials on stroke rates after clipping of intracranial aneurysms. Neurosurgery 70(5):11141124.

[128]. Quińones-Hinojosa A, Alam M, Lyon R, Yingling CD, Lawton MT (2004) Transcranial motor evoked potentials during basilar artery aneurysm surgery: technique application for 30 consecutive patients. Neurosurgery 54(4):916-924.

[129]. Gonçalves MB, Nunes CF, Melo JO Jr, Guimaraes RD, Klescoski J Jr, Landeiro JA (2012) Tension pneumoventricle after resection of a fourth ventricle choroid plexus papilloma: An unusual postoperative complication. Surg Neurol Int 3:116.

[130]. Cordella R, Acerbi F, Broggi M, Vailati D, Nazzi V, et al. (2013) Intraoperative neurophysiological monitoring of the cortico-spinal tract in imageguided mini-invasive neurosurgery. Clin Neurophysiol 124(6):1244-1254.

[131]. Dengler J, Cabraja M, Faust K, Picht T, Kombos T, et al. (2013) Intraoperative neurophysiological monitoring of extracranial-intracranial bypass procedures. J Neurosurg 119(1):207-214.

[132]. Guo L, Gelb AW (2011) The use of motor evoked potential monitoring during cerebral aneurysm surgery to predict pure motor deficits due to subcortical ischemia. Clin Neurophysiol 122(4):648-655.

[133]. Krieg SM, Schaffner M, Shiban E, Droese D, Obermuller T, et al. (2013) Reliability of intraoperative neurophysiological monitoring using motor evoked potentials during resection of metastases in motor-eloquent brain regions: clinical article. J Neurosurg 118(6):1269-1278.

[134]. Neuloh G, Simon M, Schramm J (2007) Stroke prevention during surgery for deep-seated gliomas. Neurophysiol Clin 37(6):383-389.

[135].Seidel K, Beck J, Stieglitz L, Schucht P, Raabe A (2013) The warning-sign hierarchy between quantitative subcortical motor mapping and continuous motor evoked potential monitoring during resection of supratentorial brain tumors. J Neurosurg 118(2):287-296.

[136].Su DK, Ojemann JG (2013) Electrocorticographic sensorimotor mapping. Clin Neurophysiol 124(6):1044-1048.

[137]. Szelenyi A, Gasser T, Seifert V (2008) Intraoperative neurophysiological monitoring in an open low-field magnetic resonance imaging system: clinical experience and technical considerations. Neurosurgery 63(4 Suppl 2):268-275.

[138]. Schucht P, Seidel K, Beck J, Murek M, Jilch A, et al. (2014) Intraoperative monopolar mapping during 5-ALA-guided resections of glioblastomas adjacent to motor eloquent areas: evaluation of resection rates and neurological outcome. Neurosurg Focus 37(6):E16.

[139]. Gempt J, Krieg SM, Huttinger S, Buchmann N, Ryang YM, et al. (2013) Postoperative ischemic changes after glioma resection identified by diffusion-weighted magnetic resonance imaging and their association with intraoperative motor evoked potentials. J Neurosurg 119(4):829-836. 